\title{
Influence of microbial interactions on the susceptibility of Karenia spp. to algicidal bacteria
}

\author{
Patricia B. Roth ${ }^{1,2}$, Christina M. Mikulski ${ }^{1}$, Gregory J. Doucette ${ }^{1, *}$ \\ ${ }^{1}$ Marine Biotoxins Program, NOAA/National Ocean Service, 219 Fort Johnson Road, Charleston, South Carolina 29412, USA \\ ${ }^{2}$ Graduate Program in Marine Biology, College of Charleston, Grice Marine Biological Laboratory, 205 Fort Johnson Road, \\ Charleston, South Carolina 29412, USA
}

\begin{abstract}
A bacterial strain (D38BY) belonging to the family Flavobacteriaceae and antagonistic towards an algicidal bacterium (strain S03; Flavobacteriaceae) was isolated from a culture of the red tide dinoflagellate Karenia brevis that had previously been characterized as resistant to attack by strain S03. This antagonistic bacterium increased the survival time of otherwise susceptible, bacteriafree $K$. brevis cultures in a concentration-dependent manner during exposure to the algicidal bacterium. Experimental evidence indicated that direct contact was required in order for strain D38BY to inhibit the killing activity of algicidal strain S03. While further work is needed to determine its precise mode of action, the antagonistic properties of strain D38BY provide further evidence that the resistance or susceptibility of certain algal taxa to algicidal attack can be more a function of interactions within the ambient microbial community than an intrinsic property of the alga.
\end{abstract}

KEY WORDS: Algicidal bacteria · Antagonism - CFB complex · Karenia brevis · Microbial interactions

Resale or republication not permitted without written consent of the publisher

\section{INTRODUCTION}

Complex relationships between bacteria and algae have been proposed to influence the development and termination of harmful algal blooms (HABs; Doucette 1995, Imai et al. 1998, Skerratt et al. 2002). These bacterial-algal interactions can be inhibitory or stimulatory as reported by Fukami et al. (1991), who observed that the native microbial community associated with Gymnodinium (= Karenia) mikimotoi was able to stimulate the growth of this dinoflagellate while inhibiting the growth of a potentially co-occurring diatom, Skeletonema costatum. In the specific case of algicidal bacteria, their role in regulating $\mathrm{HAB}$ population dynamics remains uncertain and an area of active investigation driven, in part, by their potential use in management and mitigation strategies (Doucette et al. 1998, 1999, Mayali \& Azam 2004, Hare et al. 2005).

Interactions between bacteria are also well documented within microbial communities. Bacteria capa- ble of producing antibiotics are commonly associated with various marine invertebrates (Jensen \& Fenical 1994, Bernan et al. 1997, Müller et al. 2004). Several Alteromonas spp. (since reclassified as Pseudoalteromonas) produce high molecular mass antibacterial compounds (Gauthier \& Flatau 1976, Gauthier \& Breittmayer 1979), some of which can diffuse into the surrounding medium whereas others remain bound to the cell surface (Andersen et al. 1974). Nair \& Simidu (1987) documented the antibacterial properties of marine heterotrophic bacteria isolated from water samples, sediment, phytoplankton, zooplankton, and sponges, with the greatest activity accompanying phytoplankton isolates. The production of antibiotics by terrestrial bacteria is well documented, particularly for microbes associated with organically rich microenvironments (Thomashow et al. 1990), which are analogous to certain substrates in the marine environment, including those investigated by Nair \& Simidu (1987) as well as detrital aggregates, such as marine snow. 
Previous studies have shown that bacteria in contact with organic matter have a greater tendency to inhibit the growth of other bacteria (Nair \& Simidu 1987, Burgess et al. 1999). Long \& Azam (2001) reported that the number of bacterial strains inhibited by attached bacteria was approximately 3 times higher than those adversely affected by free-living bacteria. Grossart et al. (2004) found that over $50 \%$ of strains isolated from marine aggregates were capable of inhibiting at least 1 other bacterium. Although these studies highlight the contributions of attached bacteria, free-living microbes also warrant consideration. Mayali \& Doucette (2002) showed that resistance and susceptibility to an algicidal bacterium could be transferred among cultures of the red tide dinoflagellate Karenia brevis simply by exchanging the native freeliving microbial communities associated with susceptible and resistant isolates. Their findings implicated interactions among bacteria as a potential mechanism for modulating the killing activity of algicidal strains. The ecological significance of antagonistic or inhibitory interactions between bacteria remains largely speculative. Nonetheless, such interactions could influence competition for nutrients or space (Holmström \& Kjelleberg 1999) and lead to changes in microbial species composition that may, in turn, alter the nature and rates of bacterially-mediated carbon cycling (Martinez et al. 1996, Long et al. 2003). A better understanding of these relationships and knowledge of the key species involved are essential for predicting their impacts on marine ecosystems. Our goal was to isolate and characterize the antagonistic microbial component(s) of a Karenia brevis culture responsible for impeding the killing activity of an algicidal bacterium reported as lethal to other $K$. brevis isolates (Doucette et al. 1999, Mayali \& Doucette 2002). This work is part of a broader effort to understand how algicidal bacteria can affect the growth of harmful algal species and to identify the factors that may influence this relationship.

\section{MATERIALS AND METHODS}

Culture conditions. Dinoflagellates: Two Karenia brevis clonal isolates originating from Charlotte Harbor, Florida, USA (C2, Dr. K. Steidinger, Fish and Wildlife Research Institute, St. Petersburg, Florida, USA; NOAA-1, Dr. S. Morton, National Ocean Service/CCEHBR, Charleston, South Carolina, USA) were made bacteria-free by treating with dihydrostreptomycin and neomycin (final concentration $250 \mu \mathrm{g} \mathrm{ml}^{-1}$ for both) as well as penicillin $G$ (final concentration $500 \mu \mathrm{g} \mathrm{ml}^{-1}$ ). Cultures were periodically confirmed to be bacteria-free by using epifluorescence microscopy
(4', 6-diamidino-2-phenylindole [DAPI] staining) and PCR amplification with eubacterial primers. Additionally, cultures of both isolates, C2 and NOAA-1, retaining their natural microbial community (= non-axenic) were also employed, resulting in a total of $4 \mathrm{~K}$. brevis isolates. $K$. mikimotoi isolates, including non-axenic (NOAA-2, origin: Sarasota, Florida, USA; Dr. S. Morton) and bacteria-free (G303ax-2, origin: Suo Nada, Japan; Dr. K. Fukami, Kochi University, Japan) cultures, were also used, based on their phylogenetic similarity to $K$. brevis. All cultures were grown in $50 \mathrm{ml}$ borosilicate glass tubes containing $25 \mathrm{ml}$ of natural seawater (30 ppt) amended with $\mathrm{f} / 2$ enrichments $\left(-\mathrm{Si}_{\text {; }}\right.$ Guillard 1973) and $0.01 \mu \mathrm{M}$ selenous acid, at $20^{\circ} \mathrm{C}$ on a 16:8 h light:dark regimen with a photon flux rate of $\sim 75 \mu \mathrm{mol} \mathrm{m} \mathrm{m}^{-2} \mathrm{~s}^{-1}$. In vivo fluorescence was measured with a fluorometer (Turner Designs, model 10-AU) and used as a proxy for algal growth. A culture was considered dead when the average relative fluorescence units (RFU) were $<10 \%$ of the controls.

Algicidal bacteria: The Flavobacteriaceae strain S03 (collected in September 2001 from the west Florida shelf, USA; Accession \# EU021292) was used to investigate the antagonistic activity associated with Karenia brevis cultures resistant to algicidal attack. One ml freezedowns of strain S03 $\left(\mathrm{LN}_{2} ; 10 \%\right.$ glycerol) were thawed, and a $100 \mu \mathrm{l}$ aliquot was added to $3 \mathrm{ml}$ of seawater complete medium (SWC; Haygood \& Nealson 1985) and grown at $20^{\circ} \mathrm{C}$ in a shaker bath for $\sim 24 \mathrm{~h}$. Cultures were centrifuged $(6500 \times g)$, and the bacterial cells were washed by resuspending in autoclaved, filtered $\left(0.22 \mu \mathrm{m}_{\text {; }}\right.$ Whatman) natural seawater (30 ppt). Bacterial cell counts were performed by epifluorescence microscropy after DAPI staining (Porter \& Feig 1980).

Experiments. Dinoflagellate susceptibility to algicidal bacteria: Twenty-five $\mathrm{ml}$ of 6 exponentially growing isolates, including bacteria-free Karenia brevis (isolates C2 and NOAA-1, each $\mathrm{n}=4$ ), non-axenic $K$. brevis (isolates $\mathrm{C} 2$ and NOAA-1, $\mathrm{n}=2$ ), bacteriafree $K$. mikimotoi (isolate G303ax-2, $\mathrm{n}=4$ ), and nonaxenic $K$. mikimotoi (isolate NOAA-2, $\mathrm{n}=2$ ), were inoculated with algicidal strain S03 at $10^{3}$ cells $\mathrm{ml}^{-1}$ or with an equivalent volume of sterile filtered $(0.22 \mu \mathrm{m})$ seawater as a negative control. Additionally, a nonalgicidal strain, Aquimarina latercula (formerly Cytophaga latercula, Accession \# D12665; Nedashkovskaya et al. 2006), was inoculated at $10^{3}$ cells $\mathrm{ml}^{-1}$ into the 3 bacteria-free Karenia spp. cultures $(n=4)$ to account for any effects caused by simply introducing a benign bacterium. Growth was monitored for $10 \mathrm{~d}$ by in vivo fluorescence.

Mode of bacterial antagonism - co-culture filtrate: Cultures of non-axenic Karenia brevis NOAA-1 ( $\mathrm{n}=4$ ) resistant to killing by bacterial strain S03 were treated 
with this algicidal bacterium $\left(10^{3}\right.$ cells $\left.\mathrm{ml}^{-1}\right)$, and algal growth was monitored over $4 \mathrm{~d}$. K. brevis $\mathrm{C} 2$ cultures $(n=4)$ also received an inoculum of strain S03 $\left(10^{3}\right.$ cells $\mathrm{ml}^{-1}$ ), serving as a positive control for the algicidal activity of this bacterium. Twenty-five $\mathrm{ml}$ from each non-axenic $K$. brevis NOAA-1 replicate were then filtered sequentially through a $5.0 \mu \mathrm{m}$ polycarbonate membrane (Poretics, Osmonics) and a $0.22 \mu \mathrm{m}$ cellulose acetate membrane (Whatman) to ensure that only dissolved compounds were retained in the filtrate. Five $\mathrm{ml}$ of this filtrate were preserved for mode of action studies as described below. The 4 replicate $20 \mathrm{ml}$ filtrates were then re-amended with $\mathrm{f} / 2$ nutrients and inoculated with bacteria-free cultures of $K$. mikimotoi G303ax-2 to a starting in vivo fluorescence of $\sim 25 \mathrm{RFU}$. Two of the replicates received an inoculum of algicidal strain S03 $\left(10^{3}\right.$ cells $\left.\mathrm{ml}^{-1}\right)$, while the other 2 replicates were inoculated with an equal volume of sterile seawater and served as controls. Growth was monitored by in vivo fluorescence every $48 \mathrm{~h}$ for $10 \mathrm{~d}$ (see Fig. 2, schematic diagram).

A Burkholder agar diffusion assay (Burkholder et al. 1966) was performed as an alternative approach to characterizing the mode of bacterial antagonism. A lawn of algicidal strain S03 was prepared by mixing $15 \mathrm{ml}$ of molten $\left(\sim 45^{\circ} \mathrm{C}\right) \mathrm{SWC}$ agar with $100 \mu \mathrm{l}$ of strain S03 liquid culture $\left(\mathrm{OD}_{660} \sim 0.5\right)$. After $24 \mathrm{~h}, 1$ of 3 sterile filter discs ( $6 \mathrm{~mm}$ diameter) was saturated with $25 \mu \mathrm{l}$ of either penicillin $\mathrm{G}\left(500 \mu \mathrm{g} \mathrm{ml} \mathrm{m}^{-1}\right.$; positive control), $0.22 \mu \mathrm{m}$ filtered seawater (negative control), or the coculture filtrate ( $\mathrm{n}=2$ for all solutions), and all 3 were placed on the lawn. The filtrate was derived from cocultures of Karenia brevis NOAA-1/strain S03 described above. Plates were sealed with parafilm, incubated for $3 \mathrm{~d}$ at $20^{\circ} \mathrm{C}$, and examined after 24,48 , and $72 \mathrm{~h}$ for zones of growth inhibition.

Isolation and classification of an antagonistic bacterium: Aliquots of Karenia brevis NOAA-1 cultures were streaked onto agar plates comprised of either dinoflagellate-bacterial growth medium (DBG/5; Doucette et al. 1999) or SWC medium. Purified colonies from these plates were screened for antagonistic activity against algicidal strain S03 in bacteria-free $K$. mikimotoi G303ax-2 cultures. Twenty-five $\mathrm{ml}$ cultures of $K$. mikimotoi in mid- to late-exponential growth phase were inoculated with strain S03 at $10^{3}$ cells $\mathrm{ml}^{-1}$ and 1 loop of a newly isolated bacterial colony. Dinoflagellate culture growth was monitored by in vivo fluorescence and compared to that of controls receiving either strain S03 $\left(10^{3}\right.$ cells $\left.\mathrm{ml}^{-1}\right)$ or sterile seawater.

During 2 rounds of screening, 1 bacterial isolate (strain D38BY) exhibited the strongest antagonistic activity and was characterized further based on its 16S rRNA gene sequence. Briefly, genomic DNA was extracted using a standard CTAB (hexadecyltrimethyl ammonium bromide) protocol, and 16S rDNA was amplified using a universal prokaryotic primer (27 F) and a Eubacteria-specific primer (1492 R) under the following conditions: $20 \mathrm{mM}$ Tris- $\mathrm{HCl}(\mathrm{pH} 8.4), 50 \mathrm{mM}$ $\mathrm{KCl}, 2.5 \mathrm{mM} \mathrm{MgCl}_{2}, 0.2 \mathrm{mM}$ each dNTP, $0.5 \mu \mathrm{M}$ each primer, and 2.5 units Taq polymerase (Invitrogen). An initial denaturating step of $5 \mathrm{~min}$ at $92^{\circ} \mathrm{C}$ was followed by 30 cycles of denaturing $\left(92^{\circ} \mathrm{C}\right)$, annealing $\left(45^{\circ} \mathrm{C}\right)$, and extension $\left(72^{\circ} \mathrm{C}\right)$, each for $45 \mathrm{~s}$. A final extension at $72^{\circ} \mathrm{C}$ ran for $7 \mathrm{~min}$ (after Mayali \& Doucette 2002). Direct sequencing of purified amplicons was performed by SeqWright DNA Technology Services (Houston, TX) on an ABI Prism ${ }^{\mathrm{TM}} 3730 \mathrm{xl}$ sequencer (Applied Biosystems). Multiple internal primers ensured that all regions were sequenced in both directions (Lane 1991). The Ribosomal Database Project-II (RDP-II; http://rdp.cme.msu.edu) was used to perform a similarity ranking (Cole et al. 2007) and hierarchical classification (Classifier Program; Wang et al. 2007).

Mode of bacterial antagonism - strain D38BY (ACcession \# EU021293): A second Burkholder agar diffusion assay was conducted using the newly isolated antagonistic bacterial strain D38BY (see above). Lawns of algicidal strain S03 (see above) received 4 discs each containing $20 \mu \mathrm{l}$ from 1 of the following treatments: (1) $10 \%$ glycerol plus sterile DBG/5 medium (negative control), (2) strain D38BY in its DBG/5 growth medium, (3) supernatant from a cell-free liquid culture of strain D38BY, (4) cells of strain D38BY washed twice and resuspended in $1 \mathrm{ml}$ of sterile $0.22 \mu \mathrm{m}$ filtered seawater. Duplicate plates were monitored for zones of growth inhibition every $24 \mathrm{~h}$ for $7 \mathrm{~d}$.

Concentration-dependent antagonistic effect: Midexponential phase, bacteria-free cultures of Karenia mikimotoi G303ax-2 were co-inoculated with algicidal bacterium strain S03 $\left(10^{3}\right.$ cells $\left.\mathrm{ml}^{-1}\right)$ and the antagonistic strain D38BY at concentrations ranging from $10^{2}$ to $10^{7}$ cells ml $\mathrm{m}^{-1}$ in 10 -fold increments (Day 6, $\mathrm{n}=3$ ). Addition of strain S03 alone $\left(10^{3}\right.$ cells $\left.\mathrm{ml}^{-1}\right)$ served as a positive control, while an equal volume of autoclaved, $0.22 \mu \mathrm{m}$ filtered seawater was used as a negative control. All treatments were performed in triplicate, and algal growth was monitored by in vivo fluorescence at $48 \mathrm{~h}$ intervals for $18 \mathrm{~d}$.

Potential non-specific effects of bacterial-overloading and nutrient competition were examined by introducing strain S03 $\left(10^{3}\right.$ cells $\left.\mathrm{ml}^{-1}\right)$ and the closely related, non-algicidal strain Aquimarina latercula (0, $10^{6}$, or $10^{7}$ cells $\mathrm{ml}^{-1}$ ) to duplicate bacteria-free Karenia mikimotoi G303ax-2 cultures on Day 6. Positive and negative controls (see above) were employed, and in vivo fluorescence was monitored every $48 \mathrm{~h}$ for $14 \mathrm{~d}$.

The specificity of strain D38BY antagonistic activity was investigated using bacteria-free Karenia miki- 
motoi G303ax-2 cultures and an algicidal bacterium (strain 5N-3, Flavobacterium sp., Accession \# AB017597) phylogenetically similar to strain S03. Strain 5N-3 kills K. mikimotoi via the release of a dissolved algicidal compound (Fukami et al. 1992). Exponentially growing algal cultures (Day 0, $\mathrm{n}=2$ ) were inoculated with strain $5 \mathrm{~N}-3\left(10^{3}\right.$ cells ml-1) and increasing concentrations of strain D38BY $\left(10^{0}\right.$ to $10^{6}$ cells $\mathrm{ml}^{-1}$ ). Positive (strain $5 \mathrm{~N}-3$ only) and negative (sterile filtered seawater) controls were included, and in vivo fluorescence was monitored every $48 \mathrm{~h}$ for $12 \mathrm{~d}$.

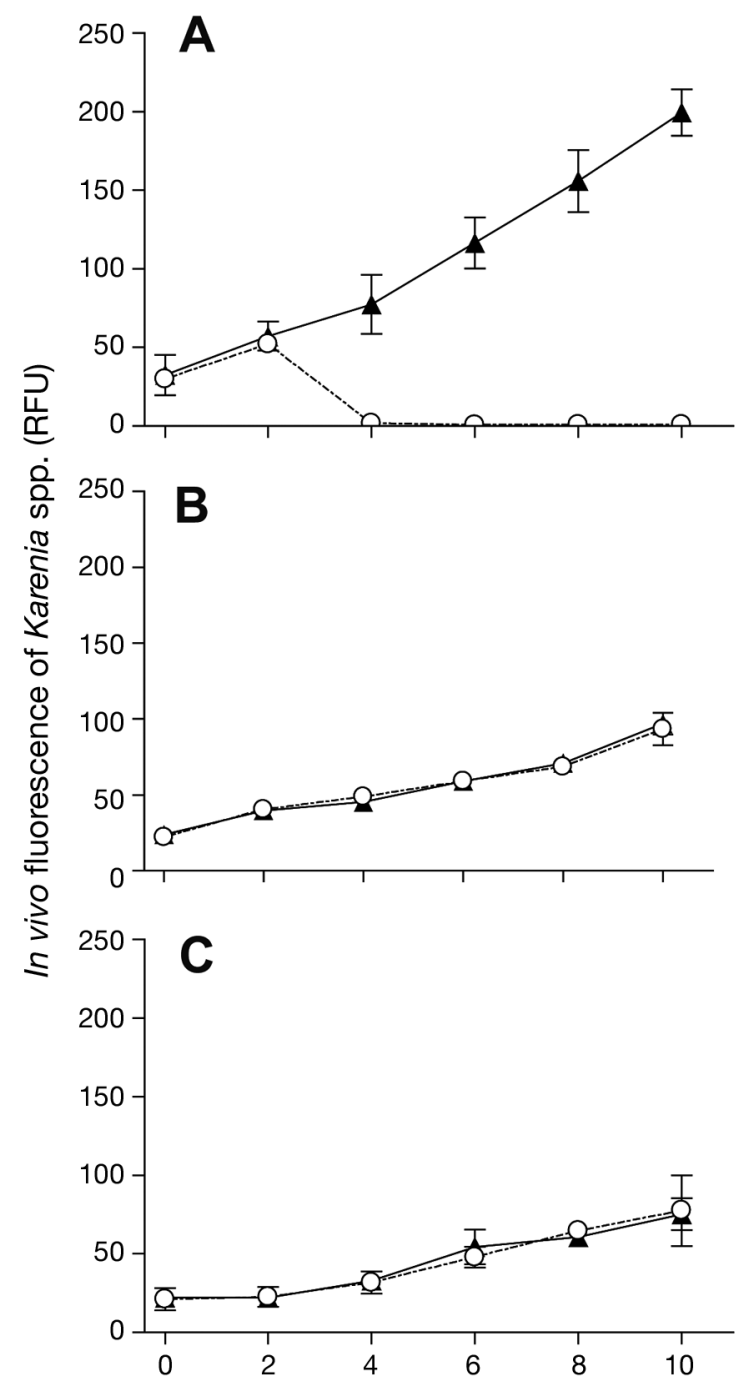

\section{RESULTS}

\section{Dinoflagellate susceptibility to algicidal bacteria}

Among the 3 isolates containing their original microbial flora, only Karenia brevis C2 was susceptible to algicidal strain S03. All C2 replicates declined to $<10$ RFU by Day 4, while both $K$. brevis NOAA-1 and $K$. mikimotoi NOAA-2 were resistant to the killing activity of strain S03 (Fig. 1A-C). Bacteria-free cultures of all 3 isolates were killed within $6 \mathrm{~d}$ of exposure to strain S03 (Fig. 1 D-F).
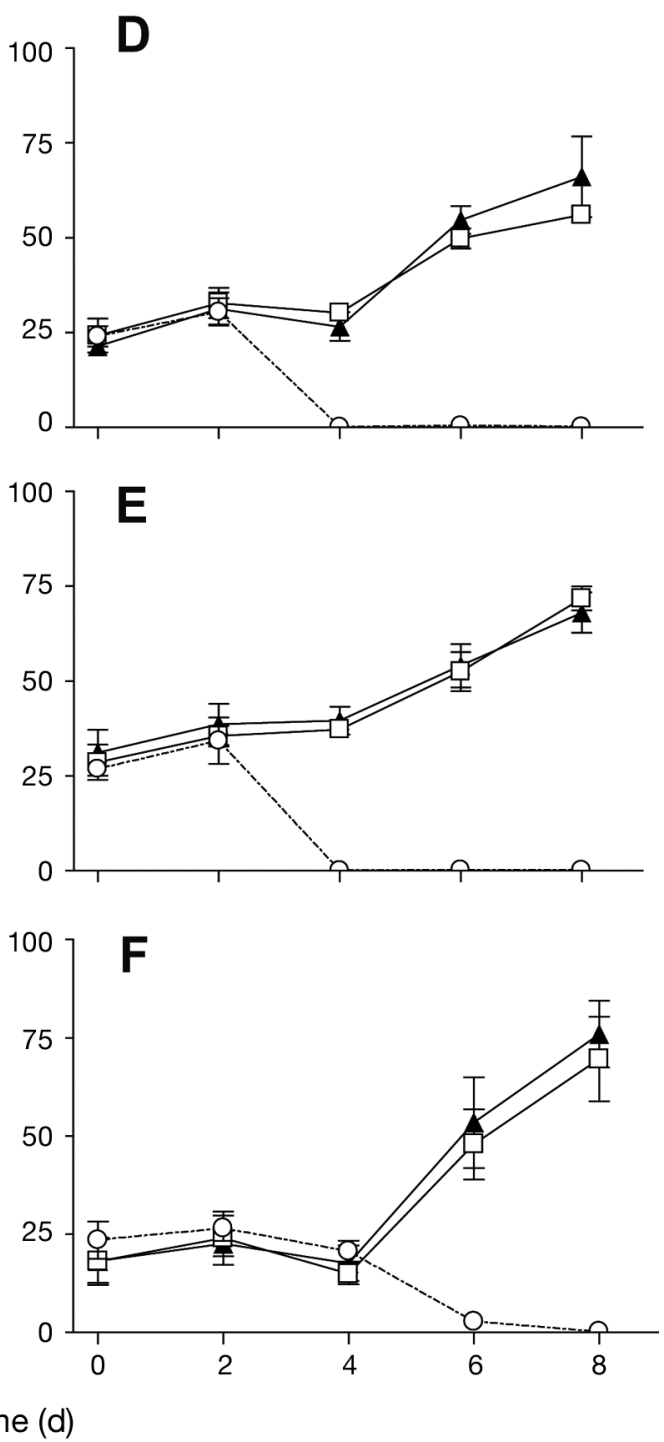

Fig. 1. Non-axenic Karenia brevis isolates (A) C2 and (B) NOAA-1, and (C) K. mikimotoi isolate NOAA-2 were inoculated with either algicidal bacterium strain S03 $\left(10^{3} \mathrm{cells} \mathrm{ml}^{-1}\right.$; O) or an equal volume of sterile filtered seawater $(\mathbf{\Delta})$ on Day $0(\mathrm{n}=2 ;$ mean \pm $1 \mathrm{SD}$ ). Bacteria-free cultures of $K$. brevis isolates (D) C2 and (E) NOAA-1, and (F) K. mikimotoi isolate G303ax-2 also received either strain S03 $\left(10^{3}\right.$ cells ml $^{-1}$; O) or sterile filtered seawater $(\boldsymbol{\Lambda})$ on Day $0(\mathrm{n}=4 ;$ mean $\pm 1 \mathrm{SE})$. In the bacteria-free cultures, additional negative controls were inoculated with a non-algicidal bacterium, Aquimarina latercula $\left(10^{3} \mathrm{cells} \mathrm{ml}^{-1}\right.$; $\left.\square\right)$ on Day $0(\mathrm{n}=$ 4 ; mean $\pm 1 \mathrm{SE}$ ). Growth was monitored by in vivo fluorescence expressed as relative fluorescence units (RFU) here and in all subsequent figures 


\section{Mode of bacterial antagonism: co-culture filtrate}

Cultures of Karenia brevis NOAA-1 treated with algicidal strain $\mathrm{S} 03$ showed a 2-fold increase in RFU between Days 6 and 8, as did the negative control cultures receiving only sterile sea water (negative control data not shown). However, the positive control $K$. brevis $\mathrm{C} 2$ cultures treated with strain S03 died by Day 8 (Fig. 2A), showing an average RFU $~ 9.6 \%$ of the negative controls (negative control data not shown).

Filtrates from the NOAA-1/S03 co-cultures (Day 8) re-amended with $f / 2$ nutrients were used as growth medium for bacteria-free Karenia mikimotoi (G303ax2) cultures. Those $K$. mikimotoi cultures inoculated with strain S03 $\left(10^{3}\right.$ cells $\left.\mathrm{ml}^{-1}\right)$ survived only $4 \mathrm{~d}$, indicating the absence (or degradation) of a dissolved antagonistic agent in the co-culture filtrate, while parallel control cultures receiving sterile seawater showed normal growth (Fig. 2 B).

To assess the possible influence of a solid substrate on antagonistic activity, filtrates from the Karenia brevis NOAA-1/S03 co-cultures were used to treat discs placed on actively growing lawns of strain S03. Discs treated with penicillin $\mathrm{G}$ (positive control) exhibited zones of growth inhibition $22 \pm 1.3 \mathrm{~mm}$ (mean $\pm \mathrm{SD}$ ), $25 \pm 2.0 \mathrm{~mm}$, and $27 \pm 1.4 \mathrm{~mm}$ in diameter after 24,48 , and $72 \mathrm{~h}$, respectively. No evidence of growth inhibition was observed for any of the treatment or negative control discs (data not shown).

\section{Isolation and classification of an antagonistic bacterium}

Twenty-six bacterial strains were isolated and purified from Karenia brevis NOAA-1 cultures and screened for antagonistic activity against bacteria-free K. mikimotoi G303ax-2 cultures inoculated with algicidal strain S03. Six of the original 26 bacterial strains, all isolated on DBG/5 plates, showed some degree of antagonism or inhibition towards the killing activity of strain S03; however, isolate D38BY was most effective in prolonging the growth of $K$. mikimotoi (data not shown).

The Classifier program on RDP-II placed the antagonistic strain D38BY bacterium within the family Flavobacteriaceae and the genus Tenacibaculum with $100 \%$ and $93 \%$ confidence, respectively. The RDP-II Sequence Match program identified an unknown bacterium, isolated originally from mucus of the coral Oculina patagonica (Accession \# AY654806), as the closest match (0.959 seqmatch score).

\section{Karenia brevis cultures}

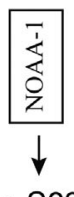

$+\mathrm{S} 03$

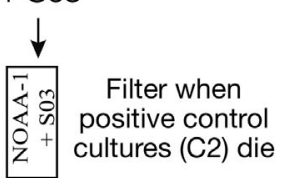

\begin{tabular}{ll|l}
$5 \mu \mathrm{m}$ & $\ldots$ & $\cdots$ \\
$0.22 \mu \mathrm{m}$ & & \\
& &
\end{tabular}

Filtrate $+f / 2$ nutrients

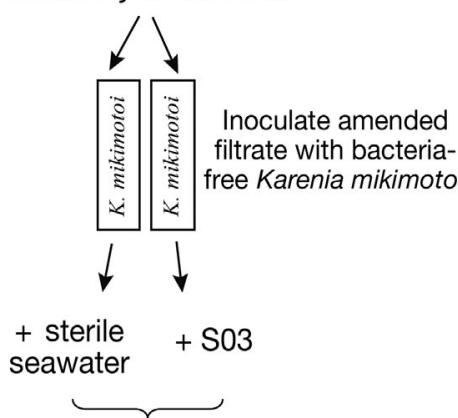

Growth monitored by in vivo fluorescence

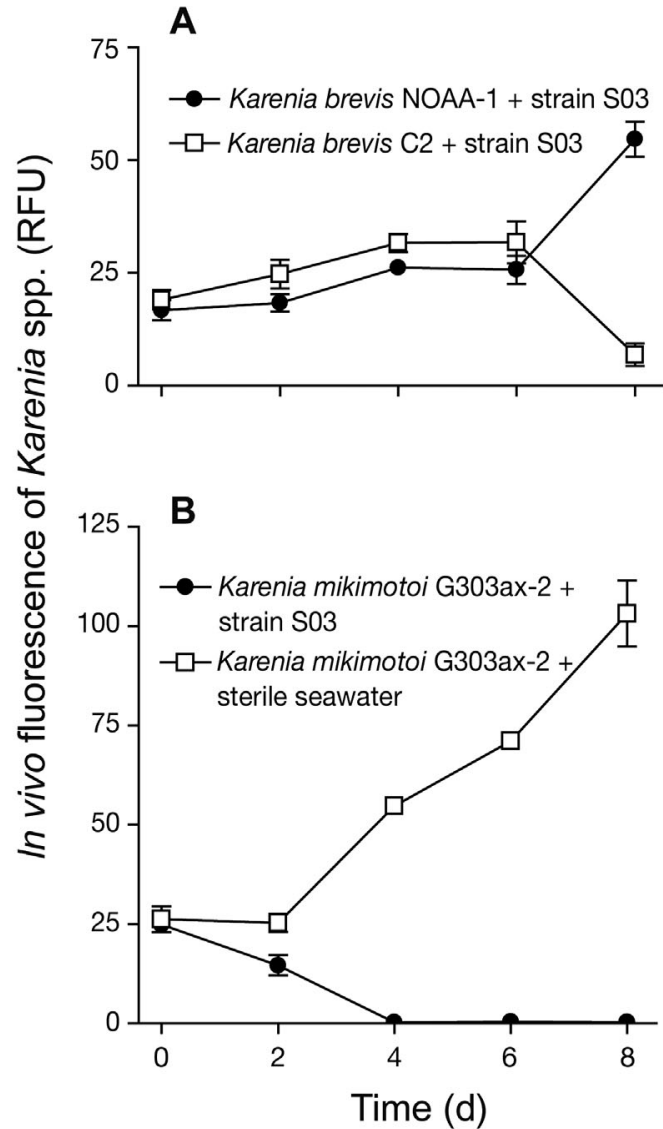

Fig. 2. Co-culture filtrate experiment. (A) Bacteria-free cultures of Karenia brevis $\mathrm{C} 2$ and NOAA-1 isolates were inoculated with algicidal strain S03 $\left(10^{3}\right.$ cells $\left.\mathrm{ml}^{-1}\right)$ on Day $4(\mathrm{n}=4$; mean $\pm 1 \mathrm{SE})$. $K$. brevis $\mathrm{C} 2$ cultures served as a positive control for the algicidal activity of strain S03. When the positive control cultures died (Day 8), filtrates from the NOAA-1/strain S03 cocultures were obtained, reamended with $\mathrm{f} / 2$ nutrients, and used as the growth medium for bacteriafree K. mikimotoi G303ax-2. (B) On Day 0, K. mikimotoi G303ax-2 and strain S03 $\left(10^{3}\right.$ cells ml $\left.{ }^{-1}\right)$ were inoculated into the NOAA-1/strain S03 re-amended co-culture filtrate $(\mathrm{n}=2$; mean $\pm 1 \mathrm{SD})$. A negative control culture received sterile filtered seawater, instead of the algicidal bacterium $(\mathrm{n}=2$; mean \pm 1 SD). Growth was monitored by in vivo fluorescence. A schematic diagram (left) illustrates the experimental protocol 


\section{Mode of bacterial antagonism: strain D38BY}

A disc diffusion assay was performed to evaluate the antagonistic mode of action for the newly isolated strain D38BY. Four discs were placed on a developing lawn of algicidal strain S03 after being treated with one of the following: fresh growth medium, liquid culture of strain D38BY, supernatant of the strain D38BY liquid culture, or washed cells of strain D38BY. No zones of growth inhibition were observed for any treatment on either replicate over the $7 \mathrm{~d}$ incubation period.

\section{Concentration-dependent antagonistic effect}

A clear concentration-dependent antagonistic or inhibitory effect was observed when increasing concentrations of strain D38BY were added to co-cultures of bacteria-free Karenia mikimotoi (G303ax-2)/algicidal strain S03. K. mikimotoi cells exposed only to strain S03 were lysed within $4 \mathrm{~d}$ i however, when strain D38BY was added concurrently at initial concentrations of $10^{4}$ and $10^{6}$ cells ml-1 ${ }^{-1}$ culture growth was prolonged by 100 and $300 \%$, respectively (Fig. 3). Lysis of the K. mikimotoi culture inoculated with strain D38BY at $10^{7}$ cells $\mathrm{ml}^{-1}$ had not occurred by completion of the experiment (i.e. Day 18) and was indistinguishable from the seawater control (Fig. 3). The lowest D38BY concentration observed to have an inhibitory effect against the killing activity of the algicidal bacterium was $10^{3}$ cells ml- $^{-1}$ (Fig. 3).

When bacteria-free Karenia mikimotoi cultures were treated concurrently with algicidal strain S03

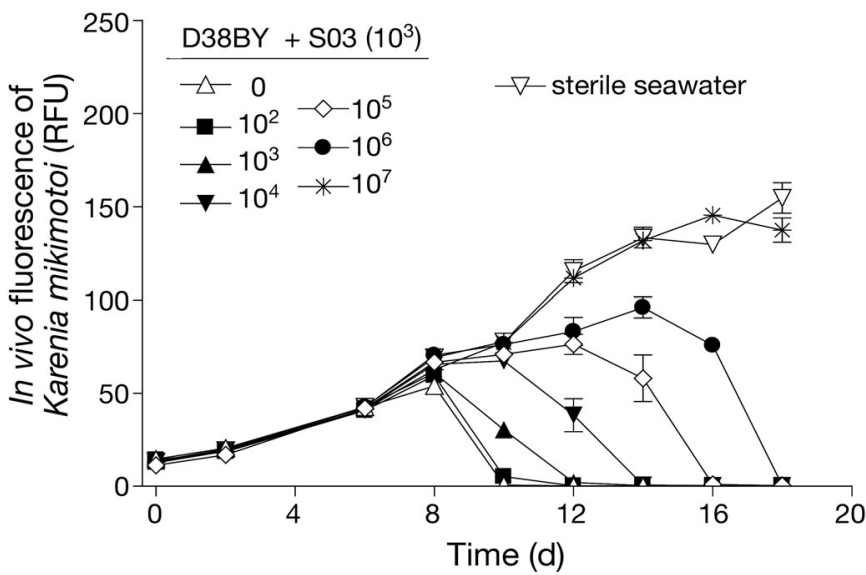

Fig. 3. Concentration-dependent activity of antagonistic strain D38BY against algicidal bacterium S03. On Day 6, $20 \mathrm{ml}$ cultures of bacteria-free Karenia mikimotoi G303ax-2 received additions of both strains $\mathrm{S} 03\left(10^{3}\right.$ cells $\left.\mathrm{ml}^{-1}\right)$ and D38BY ( 0 to $10^{7}$ cells $\mathrm{ml}^{-1}, 10$-fold increments). Negative control cultures received an equal volume of sterile filtered seawater instead of strain D38BY. Growth was monitored every $48 \mathrm{~h}$ by in vivo fluorescence $(\mathrm{n}=3$; mean $\pm 1 \mathrm{SE})$ $\left(10^{3}\right.$ cells $\left.\mathrm{ml}^{-1}\right)$ and the closely related, but non-algicidal, Aquimarina latercula at $0,10^{6}$, or $10^{7} \mathrm{cells} \mathrm{ml}^{-1}$, no inhibition of algicidal activity was observed, suggesting that non-specific effects of bacterial overloading or nutrient competition were not significant. All cultures receiving bacterial additions were killed within $4 \mathrm{~d}$ of inoculation, whereas controls receiving sterile filtered seawater continued to grow throughout the time course (Fig. 4).

Similarly, an experiment designed to test the specificity of antagonistic strain D38BY against an alternate algicidal bacterium (strain $5 \mathrm{~N}-3$ ) revealed no inhibitory effects. Co-cultures of Karenia mikimotoi (G3030ax-2)/algicidal bacterial strain 5N-3 receiving increasing concentrations of strain D38BY were all killed within $4 \mathrm{~d}$ of inoculation (Fig. 5). Control cultures receiving sterile filtered seawater grew normally during the experiment.

\section{DISCUSSION}

Studies examining the relationship between algicidal bacteria and phytoplankton have focused primarily on the killing of target algal cells by bacteria, while placing little emphasis on the factors influencing this interaction. The susceptibility or resistance of Karenia brevis cultures to attack by an algicidal bacterium

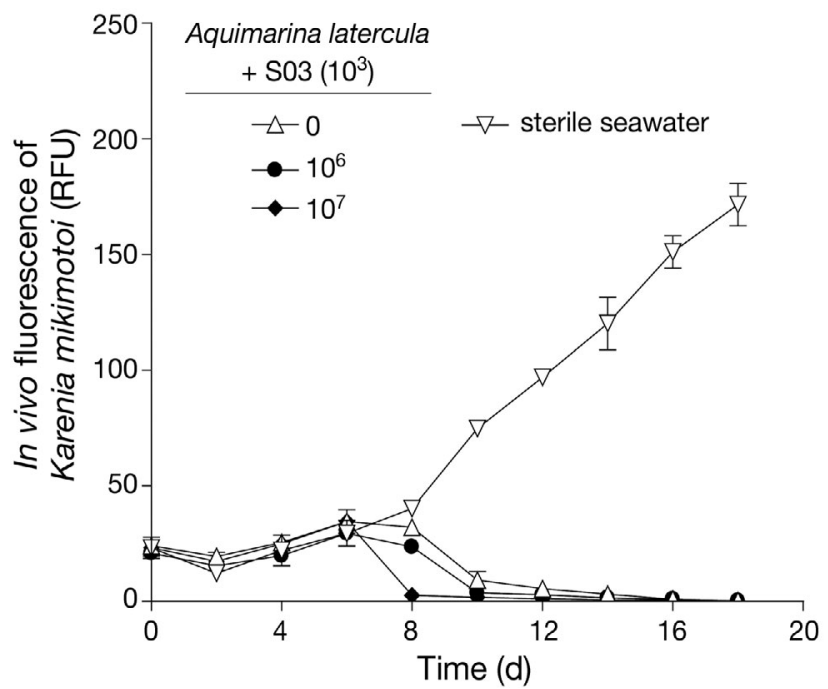

Fig. 4. Aquimarina latercula, a bacterium closely related to algicidal strain S03, exhibits no antagonism against the algicidal activity of strain S03. On Day 6, $20 \mathrm{ml}$ cultures of bacteria-free Karenia mikimotoi G303ax-2 received additions of both strains S03 $\left(10^{3}\right.$ cells ml $\left.{ }^{-1}\right)$ and A. latercula $\left(0,10^{6}\right.$, or $10^{7}$ cells $\mathrm{ml}^{-1}$ ). Negative control cultures received an equal volume of sterile filtered seawater instead of A. latercula. Growth was monitored every $48 \mathrm{~h}$ by in vivo fluorescence $(\mathrm{n}=2$; mean $\pm 1 \mathrm{SD})$ 


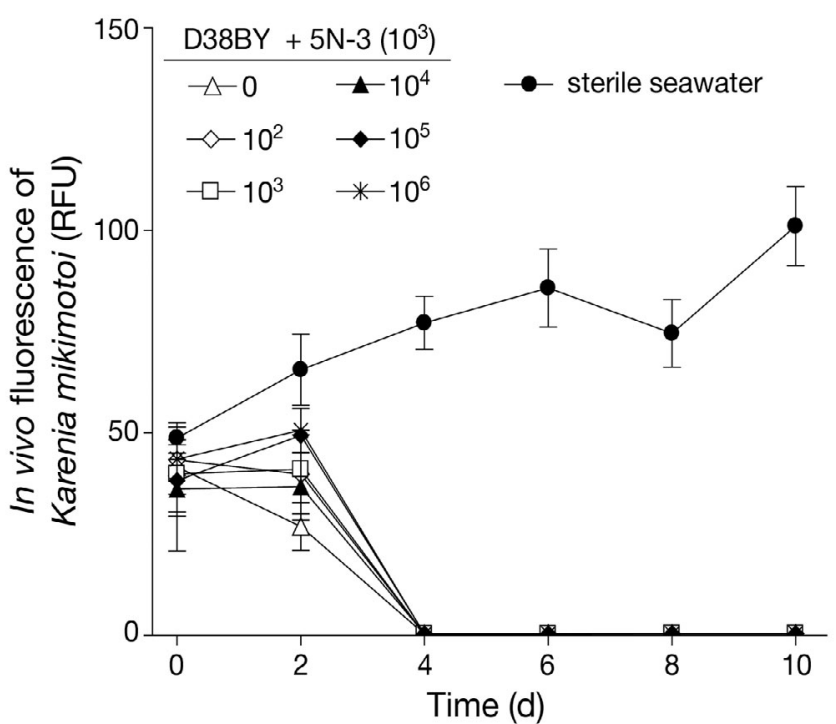

Fig. 5. Specificity of antagonistic strain D38BY, as demonstrated by a lack of inhibition against the algicidal activity of bacterium 5N-3. On Day 0, $20 \mathrm{ml}$ cultures of bacteria-free Karenia mikimotoi G303ax-2 received additions of both strains $5 \mathrm{~N}-3\left(10^{3}\right.$ cells $\left.\mathrm{ml}^{-1}\right)$ and D38BY $\left(0\right.$ to $10^{6}$ cells $\mathrm{ml}^{-1}$, 10 -fold increments). Negative control cultures received an equal volume of sterile filtered seawater instead of strain D38BY. Growth was monitored every $48 \mathrm{~h}$ by in vivo fluorescence $(n=2$; mean \pm 1 SD)

(strain 41-DBG2, Cytophaga sp.) is a function of the ambient microbial community associated with individual dinoflagellate isolates and not an intrinsic property of the algal cells (Mayali \& Doucette 2002). Remarkably, here we demonstrated the same phenomenon for $2 K$. brevis isolates (C2 and NOAA-1) as well as K. mikimotoi, in response to a newly isolated algicidal bacterium (strain S03, Flavobacteriaceae). While nonaxenic $K$. brevis NOAA-1 and $K$. mikimotoi NOAA-2 cultures were unaffected by strain S03, non-axenic $K$. brevis C2 cultures, bacteria-free cultures of both of these $K$. brevis isolates, and a bacteria-free $K$. mikimotoi isolate (G303ax-2) were killed rapidly. These findings are consistent with the hypothesis of Mayali \& Doucette (2002), that 1 or more components of the ambient bacterial flora associated with an algal isolate resistant to attack act in an antagonist manner towards algicidal bacteria, while removal of all associated bacteria generally renders algal cells susceptible to these microbes.

We isolated a bacterium (strain D38BY) from a resistant Karenia brevis culture (NOAA-1) that was capable of inhibiting the algicidal activity of bacterial strain S03. Moreover, the antagonistic or inhibitory properties of strain D38BY prolonged the growth of bacteriafree $K$. mikimotoi cultures exposed to strain S03 in a concentration dependent manner. This antagonistic bacterium is likely one of several functionally similar taxa present in the $K$. brevis NOAA-1 microbial assemblage, consistent with our isolation of several bacteria exhibiting weaker antagonistic activity relative to strain D38BY. Since less than 1\% of marine bacteria are considered to be cultivable (Muyzer \& Smalla 1998), additional strains capable of inhibiting the killing activity of algicidal bacteria are probably present in this and other $K$. brevis cultures. The fact that increasing concentrations of strain D38BY $\left(10^{2}\right.$ to $10^{6}$ cells $\mathrm{ml}^{-1}$ ) had no inhibitory effect on an algicidal bacterium (strain 5N-3, Flavobacterium sp.) producing a dissolved algicidal agent(s) indicates the potentially specific or selective nature of such antagonistic interactions. While the mechanism of inhibition remains uncertain (see below), our finding that the algicidal activity of strain S03 remained unaffected by elevated concentrations $\left(10^{6}\right.$ and $10^{7}$ cells $\left.\mathrm{ml}^{-1}\right)$ of another member of the family Flavobacteriaceae suggests that non-specific interactions (e.g. nutrient competition) play a minimal role.

Interestingly, the closest taxonomic relative to strain D38BY was isolated from mucus of the coral Oculina patagonica. Corals rely on photosynthetic dinoflagellate endosymbionts (i.e. zooxanthellae) to provide over $60 \%$ of their nutrient requirement (Glynn 1991). Disruption of this mutualistic relationship leads to bleaching and often death of the coral. Kushmaro et al. (1996) identified a bacterium, Vibrio shiloi, capable of killing the zooxanthellae residing in O. patagonica and causing bleaching of the coral. Given that strain D38BY inhibits the killing activity of the algicidal bacterium strain S03, we speculate that the closely related bacterium isolated from the mucus layer of $O$. patagonica could serve to protect the zooxanthellae from attack by other algicidal bacteria. Such a scenario may not be unexpected, in view of the increasing number of examples of antagonism within marine microbial communities.

Results of filtrate and disc diffusion experiments suggest that direct contact is required for strain D38BY to inhibit the activity of algicidal strain S03, thereby arguing against the presence of a soluble bioactive compound. While it is possible that a cell-bound antibiotic(s) may be involved, inhibition of algicidal activity may also involve a competitive or predator-prey interaction that could not be identified by these methods. Alternatively, a dissolved antagonistic compound may have been released into the medium by strain D38BY, but was degraded before inhibiting the activity or growth of the algicidal bacterium. Additional work will be required to elucidate the true nature of this antagonistic interaction.

Since the discovery of the first antibiotic-producing marine bacterium by Burkholder et al. (1966), our 
knowledge of interactions among bacteria has advanced relatively little, with much of the available information being derived from studies of cultured isolates (Lemos et al. 1991, Long \& Azam 2001, Brinkhoff et al. 2004). The benefit of antibiosis within marine ecosystems remains unknown, but several hypotheses have been proposed: (1) regulation of bacterial community structure (Long et al. 2003), (2) protection from predators (Holmström \& Kjelleberg 1999), and (3) inhibition of settlement by potential competitors (Burgess et al. 1999). In addition, most research has focused on antagonistic relationships that involve the release of dissolved secondary metabolites (e.g. antibiotics), whereas interactions requiring direct contact between bacteria have been largely overlooked. Considering the potential role of bacteria in the termination of HABs (Kim et al. 1998, Manage et al. 2001), as well as their involvement in biogeochemical cycles (Martinez et al. 1996), there is a clear need to continue examining antagonistic or inhibitory interactions among bacteria both within and apart from harmful algal blooms.

With specific reference to evaluating the potential use of biological agents such as bacteria and viruses to control HABs (e.g. Nagasaki et al. 1994, Hare et al. 2005), a high degree of species-specificity would be required so as to limit the impacts on other cooccurring taxa. However, our findings and those of Mayali \& Doucette (2002) indicate that the target specificity of algicidal bacteria, in particular, may be influenced more by the ambient microbial community than by the susceptibility of algal taxa to attack. Consequently, interactions within co-occurring bacterial assemblages must be considered when developing $\mathrm{HAB}$ control strategies that may involve the use of such biological agents.

Acknowledgements. We thank Drs. K. Steidinger, K. Fukami, and S. Morton for donating the original Karenia spp. cultures. Dr. M. Twiner provided valuable support throughout the project, and Dr. J. Stewart, J. Miller-Morey, and K. Jones contributed insightful reviews of this manuscript. Support for this research was provided by the US ECOHAB Program sponsored by NOAA, the US EPA, NSF, NASA, and ONR, and by NOAA/NOS operational funds. This is contribution number 255 from the US ECOHAB Program.

NOAA Disclaimer. This publication does not constitute an endorsement of any commercial product or intend to be an opinion beyond scientific or other results obtained by the National Oceanic and Atmospheric Administration (NOAA). No reference shall be made to NOAA, or this publication furnished by NOAA, to any advertising or sales promotion which would indicate or imply that NOAA recommends or endorses any proprietary product mentioned herein, or which has as its purpose an interest to cause the advertised product to be used or purchased because of this publication

\section{LITERATURE CITED}

Andersen RJ, Wolfe MS, Faulkner DJ (1974) Autotoxic antibiotic production by a marine Chromobacterium. Mar Biol 27:281-285

Bernan VS, Greenstein M, Maiese WM (1997) Marine microorganisms as a source of new natural products. Adv Appl Microbiol 43:57-89

Brinkhoff T, Bach G, Heidorn T, Liang L, Schlingloff A, Simon M (2004) Antibiotic production by a Roseobacter cladeaffiliated species from the German Wadden Sea and its antagonistic effects on indigenous isolates. Appl Environ Microbiol 70:2560-2565

Burgess JG, Jordan EM, Bregu M, Mearns-Spragg A, Boyd KG (1999) Microbial antagonism: a neglected avenue of natural products research. J Biotechnol 70:27-32

Burkholder PR, Pfister RM, Leitz F (1966) Production of a pyrrole antibiotic by a marine bacterium. J Appl Microbiol 14:649-653

Cole JR, Chai B, Farris RJ, Wang Q and others (2007) The ribosomal database project (RDP-II): introducing myRDP space and quality controlled public data. Nucleic Acids Res 35(Database issue):D169-D172

Doucette GJ (1995) Interactions between bacteria and harmful algae: a review. Nat Toxins 3:65-74

Doucette GJ, Kodama M, Franca S, Gallacher S (1998) Bacterial Interactions with harmful algal bloom species: bloom ecology, toxigenesis, and cytology. In: Anderson D, Cembella AD, Hallegraeff GM (eds) Physiological ecology of harmful algal blooms, Vol G 41. Springer-Verlag, Berlin, p 619-647

Doucette GJ, McGovern ER, Babinchak JA (1999) Algicidal bacteria active against Gymnodinium breve (Dinophyceae). I. Bacterial isolation and characterization of killing activity. J Phycol 35:1447-1454

Fukami K, Nishijima T, Murata H, Doi S, Hata Y (1991) Distribution of bacteria influential on the development and the decay of Gymnodinium nagasakiense red tide and their effects on algal growth. Nippon Suisan Gakkaishi 57: 2321-2326

Fukami K, Yuzawa A, Nishijima T, Hata Y (1992) Isolation and properties of a bacterium inhibiting the growth of Gymnodinium nagasakiense. Nippon Suisan Gakkaishi 58:1073-1077

Gauthier MJ, Breittmayer VA (1979) A new antibioticproducing bacterium from seawater: Alteromonas aurantia sp. nov. Int J Syst Bacteriol 29:366-372

> Gauthier MJ, Flatau GN (1976) Antibacterial activity of marine violet-pigmented Alteromonas with special reference to the production of brominated compounds. Can J Microbiol 22:1612-1619

Glynn PW (1991) Coral reef bleaching in the 1980s and possible connections with global warming. Trends Ecol Evol 6:175-179

- Grossart HP, Schlingloff A, Bernhard M, Simon M, Brinkhoff $T$ (2004) Antagonistic activity of bacteria isolated from organic aggregates of the German Wadden Sea. FEMS Microbiol Ecol 47:387-396

Guillard RRL (1973) Division rates. In: Stein JR (ed) Culture methods and growth measurements. Cambridge University Press, New York, p 289-311

- Hare CE, Demir E, Ciyne KJ, Cary SC, Kirchman DL, Hutchins DA (2005) A bacterium that inhibits the growth of Pfiesteria piscicida and other dinoflagellates. Harmful Algae 4:221-234

Haygood MG, Nealson K (1985) Mechanisms of iron regulation of luminescence in Vibrio fischeri. J Bacteriol 162: $209-216$ 
Holmström C, Kjelleberg S (1999) Marine Psuedoalteromonas species are associated with higher organisms and produce biologically active extracellular agents. FEMS Microbiol Ecol 30:285-293

Imai I, Kim MC, Nagasaki K, Itakura S, Ishida Y (1998) Relationships between dynamics of red tide-causing raphidophycean flagellates and algicidal microorganisms in the coastal sea of Japan. Phycol Res 46:139-146

Jensen PR, Fenical W (1994) Strategies for the discovery of secondary metabolites from marine bacteria: ecological perspectives. Annu Rev Microbiol 48:559-585

Kim MC, Yoshinaga I, Imai I, Nagasaki K, Itakura S, Ishida Y (1998) A close relationship between algicidal bacteria and termination of Heterosigma akashiwo (Raphidophyceae) blooms in Hiroshima Bay, Japan. Mar Ecol Prog Ser 170: 25-32

Kushmaro A, Loya Y, Fine M, Rosenberg E (1996) Bacterial infection and coral bleaching. Nature 380:396

Lane DJ (1991) 16S/23S rRNA sequencing. In: Stackebrandt E, Goodfellow M (eds) Nucleic acid techniques in bacterial systematics. John Wiley \& Sons, Chichester, p 115-175

Lemos ML, Dopazo CP, Toranzo AE, Barja JL (1991) Competitive dominance of antibiotic-producing marine bacteria in mixed cultures. J Appl Bacteriol 71:228-232

- Long RA, Azam F (2001) Antagonistic interactions among marine pelagic bacteria. Appl Environ Microbiol 67: 4975-4983

Long RA, Qureshi A, Faulkner DJ, Azam F (2003) 2-n-Pentyl4-Quinolinol produced by a marine Alteromonas sp. and its potential ecological and biogeochemical roles. Appl Environ Microbiol 69:568-576

Manage PM, Kawabata Z, Nakano S (2001) Dynamics of cyanophage-like particles and algicidal bacteria causing Microcystis aeruginosa mortality. Limnology 2:73-78

Martinez J, Smith DC, Steward GF, Azam F (1996) Variability in ectohydrolytic enzyme activities of pelagic marine bacteria and its significance for substrate processing in the sea. Aquat Microb Ecol 10:223-230

Mayali X, Azam F (2004) Algicidal bacteria in the sea and their impact on algal blooms. J Eukaryot Microbiol 51: 139-144

Editorial responsibility: Paul del Giorgio, Montréal, Québec, Canada
Mayali X, Doucette GJ (2002) Microbial community interactions and population dynamics of an algicidal bacterium active against Karenia brevis (Dinophyceae). Harmful Algae 1:277-293

Müller WEG, Grebenjuk VA, Le Pennec G, Schröder HC and others (2004) Sustainable production of bioactive compounds by sponges-cell culture and gene cluster approach: a review. Mar Biotechnol 6:105-117

Muyzer G, Smalla K (1998) Application of denaturing gradient gel electrophoresis (DGGE) and temperature gradient gel electrophoresis (TGGE) in microbial ecology. Antonie Van Leeuwenhoek 73:127-141

Nagasaki K, Ando M, Itakura S, Imai I, Ishida Y (1994) Viral mortality in the final stage of Heterosigma akashiwo (Raphidophyceae) red tide. J Plankton Res 16:1595-1599

Nair S, Simidu U (1987) Distribution and significance of heterotrophic marine bacteria with antibacterial activity. Appl Environ Microbiol 53:2957-2962

Nedashkovskaya OI, Vancanneyt M, Christiaens L, Kalinovskaya NI, Mikhailov VV, Swings J (2006) Aquimarina intermedia sp. nov., reclassification of Stanierella latercula (Lewin 1969) as Aquimarina latercula comb. nov. and Gaetbulimicrobium brevivitae Yoon et al. 2006 as Aquimarina brevivitae comb. nov. and emended description of the genus Aquimarina. Int J Syst Evol Microbiol 56: 2037-2041

Porter KG, Feig YS (1980) The use of DAPI for identifying and counting aquatic microflora. Limnol Oceanogr 25: 943-948

Skerratt JH, Bowman JP, Hallegraeff G, James S, Nichols PD (2002) Algicidal bacteria associated with blooms of a toxic dinoflagellate in a temperate Australian estuary. Mar Ecol Prog Ser 244:1-15

> Thomashow LS, Weller DM, Bonsall RF, Pierson LS (1990) Production of the antibiotic phenazine-1-carboxylic acid by fluorescent Pseudomonas species in the rhizosphere of wheat. Appl Environ Microbiol 56:908-912

> Wang Q, Garrity GM, Tiedje JM, Cole JR (2007) Naïve Bayesian classifier for rapid assignment of rRNA sequences into the new bacterial taxonomy. Appl Environ Microbiol 73:5261-5267

Submitted: December 6, 2006; Accepted: November 20, 2007 Proofs received from author(s): February 5, 2008 